See Article page 192.

\section{Commentary: Five "Ws" of pulmonary arterioplasty for lung transplantation: Who, what, why, and where}

\author{
Jonathan C. Yeung, MD, PhD, FRCSC
}

Pulmonary artery (PA) anastomosis during lung transplantation requires consideration of the length and diameter of the 2 vessels being anastomosed. Leaving the vessels long facilitates anastomosis, but risks postoperative kinking after the lung is inflated in a closed chest. ${ }^{1,2}$ Diameter discrepancy requires the careful circumferential narrowing of the larger vessel to match the smaller vessel, but inadvertent unequal suturing ratios may result in twisting, structuring, or narrowing of the anastomosis. This may result in turbulent flow, intraluminal thrombosis, or reduced flow to that lung, something of significance in single-lung transplantation. Yokoyama and colleagues ${ }^{4}$ describe 4 methods of pulmonary arterioplasty used at their center, a high-volume living donor lung transplant center where significant pulmonary arterial size mismatches are probably more likely to be encountered.

Four major techniques are described, all of which aim to size-reduce the larger vessel before anastomosis such that a 1:1 suture distance ratio between donor and recipient can be achieved. All 4 methods can be generalized to the deceased donor lung transplant situation more familiar to most readers of the article, with the autopericardial patch technique being a maneuver likely to be employed only during inadvertent injury of the vessel.

\footnotetext{
From the Division of Thoracic Surgery, Department of Surgery, Toronto General Hospital, University of Toronto, Toronto, Ontario, Canada.

Disclosures: The author reported no conflicts of interest.

The Journal policy requires editors and reviewers to disclose conflicts of interest and to decline handling or reviewing manuscripts for which they may have a conflict of interest. The editors and reviewers of this article have no conflicts of interest.

Received for publication June 21, 2021; revisions received June 21, 2021; accepted for publication June 28, 2021; available ahead of print July 1, 2021.

Address for reprints: Jonathan C. Yeung, MD, PhD, FRCSC, Division of Thoracic Surgery, Department of Surgery, Toronto General Hospital, University of Toronto, 200 Elizabeth St, 9N-949, Toronto, Ontario M5G 2C4, Canada (E-mail: jonathan. yeung@uhn.ca).

JTCVS Techniques 2021;9:197-8

2666-2507

Copyright (C) 2021 The Author(s). Published by Elsevier Inc. on behalf of The American Association for Thoracic Surgery. This is an open access article under the CC BY-NC-ND license (http://creativecommons.org/licenses/by-nc-nd/4.0/).

https://doi.org/10.1016/j.xjtc.2021.06.038
}

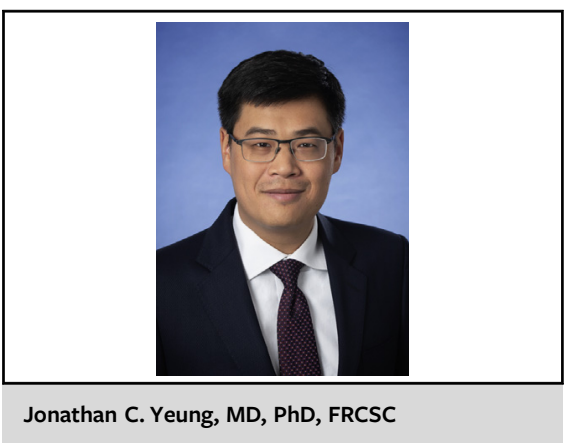

CENTRAL MESSAGE

Techniques of pulmonary arterioplasty for size mismatch during lung transplantation can be important, but surgeons need to know when it is best to utilize them.

In the review of their experience, 19 patients out of $263(7.2 \%)$ required arterioplasty, where tack suture was the technique most commonly used in the deceased donor population. No postoperative anastomotic complications were identified following these arterioplasties and suggest safety.

The major missing piece of this article is the last "W": When? Having read this article, surgeons encountering a major PA size mismatch may wish to employ 1 of these techniques. When is it necessary? When is this superior to conventional end-to-end size reduction? And, when should each of the 4 techniques be utilized? PA vessels are generally low-pressure and large and therefore more forgiving than smaller vascular anastomoses, so perhaps these are techniques borne from and necessary only in living donor lung transplantation. Indeed, with this group's unique experience in living donor lung transplantation, they have the unique potential to prospectively and comprehensively measure PA size mismatches and demonstrate when arterioplasty might be superior to circumferential correction.

Regardless, these techniques and their outcomes should be known to lung transplant surgeons even if not routinely employed. The "when" may yet become obvious at 3 Am during a difficult lung implantation. I look forward to learning more from the authors in the future about when these techniques are best employed. 


\section{References}

1. Chen F, Tazaki J, Shibata T, Miwa S, Yamazaki K, Ishii H, et al. Stent angioplasty for a kink in the pulmonary artery anastomosis soon after living-donor lobar lung transplantation. Ann Thorac Surg. 2011;92:e105-6.

2. Banerjee SK, Santhanakrishnan K, Shapiro L, Dunning J, Tsui S, Parmar J. Successful stenting of anastomotic stenosis of the left pulmonary artery after single lung transplantation. Eur Respir Rev. 2011;20:59-62.
3. Griffith BP, Magee MJ, Gonzalez IF, Houel R, Armitage JM, Hardesty RL, et al. Anastomotic pitfalls in lung transplantation. J Thorac Cardiovasc Surg. 1994;107: 743-53.

4. Yokoyama Y, Chen-Yoshikawa TF, Nakajima D, Ohsumi A, Date H. Various techniques for anastomosis of pulmonary arteries with size mismatch during lung transplantation. J Thorac Cardiovasc Surg Tech. 2021;9:192-4. 